\title{
Evaluation of foliar fungal endophyte diversity and colonization of medicinal plant Luehea divaricata (Martius et Zuccarini)
}

\author{
Juliana Bernardi-Wenzel' ; Adriana García²; Celso J R Filho3; Alberto J Prioli²; João A Pamphile²* \\ ${ }^{1}$ Higher Institute for Biological, Medical and Health Sciences - Universidade Paranaense - UNIPAR. \\ 2 Department of Cell Biology and Genetics - Universidade Estadual de Maringá. \\ 3 Department of Biology - Universidade Estadual de Maringá.
}

\begin{abstract}
Endophyte microorganisms are organisms that live inside plants without causing any apparent damage to their hosts. Since all plants exhibit endophyte microorganisms, it is believed that mutual association is of great importance in nature. Luehea divaricata (Martius \& Zuccarini), known popularly in Brazil as açoita-cavalo, is a big-sized tree with a wide distribution in the country that possesses medicinal qualities for: dysentery, leucorrhea, rheumatism, blennorrhoea, tumors, bronchitis, and depuration. This research aims at isolating and molecularly characterizing fungi isolates from L. divaricata by sequence analysis of ITS1-5.8S-ITS2 rDNA. Further, the colonization of endophyte in the host plant by Light and Scanning Electron Microscopy will also be investigated. Whereas, genera Alternaria, Cochliobolus, Diaporthe, Epicoccum, Guignardia, Phoma, and Phomopsis, were identified; rDNA sequence analysis revealed intra-species variability among endophyte isolates of the genus Phomopsis sp. Light and Scanning Electron Microscopy techniques showed the presence of endophyte fungi inside L. divaricata leaves, inhabiting inter- and intra-cellular spaces. These types of extensive colonization and dissemination were reported throughout all the leaf parts in palisade parenchyma, esclerenchyma, spongy parenchyma, adaxial epidermis, and vascular bundle indicating colonization of endophytes in multiple structural sub-niches in the host plant.
\end{abstract}

Key terms: endophyte fungi; Luehea divaricata; diversity; rDNA sequencing; Scanning Electron Microscopy.

\section{INTRODUCTION}

Endophyte microorganisms or endophytes are organisms that inhabit, at least during a period of their life cycle, a plant's interior without causing any damage to the host (Azevedo et al. 2000).

The colonization of plants by endophyte fungi occurs in a passive way since openings already exist, either in the epidermis or through the stomata. After entering, endophyte fungi disseminate systemically throughout the plant and inhabit mainly its aerial parts, conduction vessels, intercellular spaces, and in some cases they colonize the cells' interior. They may even be found in seeds (PeixotoNeto et al. 2002).

One or two endophyte species are frequently predominant in a specific host, while other isolates are rare (Carroll and Carroll 1978; Arnold et al. 2003). The close association between endophytes and plant species, with a high degree of specialization in interactions, is a possible indication that the species have evolved together (Saikkonen et al. 2004). This phenomenon has been reported by Pamphile and Azevedo (2002) in studies with corn seeds (Zea mays) containing the endophyte fungi (Fusarium verticilloides). In those studies, they were able to separate endophytic strains of $F$. verticillioides by different seed genotypes (performing RAPD analysis of endophytic fungi strains). This fact showed a strong association between them, which the authors indicated to be specific to the genotype. Furthermore, the study of Pamphile and Azevedo (2002) was one of the first to report that endophytic strains of Fusarium have been associated with inbred maize lines.
To assess the potential of endophytic fungi as vectors for introducing desirable characteristics into host tropical plants of biotechnological and agricultural importance, Pamphile et al. (2004) successfully introduced an endophyte strain of Fusarium verticillioides, co-transformed by genes nia and gus A genes, in Zea mays. The authors reported gus A gene as an expression (phenotype GUS+) of the transformed endophyte inside the cells of maize roots.

Luehea divaricata Mart. (Tiliaceae) is a big-sized tree (15 to $25 \mathrm{~m})$; it is popularly known as açoita-cavalo and may be found in several Brazilian states, from Rio Grande do Norte to Rio Grande do Sul (Alice et al. 1995; Lorenzi 2000). According to Tanaka et al. (2005), Luehea leaves are sold as phytotherapic products for dysentery, leucorrhea, rheumatism, blennorrhoea, and tumors. The infusion of its flowers is used to cure bronchitis, while the root has depurative assets.

The rDNA sequencing analysis could be used to estimate endophytic fungi diversity. The genes most employed in the fungi's phylogenetic analysis are ribosomal genes. Within the rDNA locus, the ITS region has been particularly useful for analysis of closely related fungal species in many genera (Redberg et al. 2003, Zervakis et al. 2004, Stefani and Berube 2006). The rRNA gene unit is composed of the Internal Transcribed Spacer (ITS) and the sequences of the coding rRNAs.

The Scanning Electron Microscopy (SEM) has been used as an important tool to better understand the interactions between endophytes and host plants. SEM offers unique advantages, such as high resolution and large depth of field (Pamphile et al. 2008a).

\footnotetext{
* Corresponding Author: João A. Pamphile. Universidade Estadual de Maringá - Av. Colombo, n. 5790 - CEP 87020-900 - Maringá PR Brazil. e-mail: japamphile@uem.br. Tel: +44-326-14342 / Fax: +44-326-14893.

Received: December 24, 2008. In revised form: December 3, 2009. Accepted: June 3, 2010.
} 
Due to the relevance of an in-depth study of microbial endophytes living in the medicinal host plant, this research provides the isolation and the evaluation of diversity of foliar fungal endophytes of L. divaricata.

\section{METHODS}

\section{Site of plant collection}

Leaf samples used in this study were from two trees on the campus of the State University of Maringá, Maringá PR Brazil. The first tree lies at $23^{\circ} 24^{\prime} 19.22^{\prime \prime} \mathrm{S}$ and $51^{\circ} 56^{\prime} 16.33^{\prime \prime} \mathrm{W}$; the second tree lies at $23^{\circ} 24^{\prime} 21.77^{\prime \prime} \mathrm{S}$ and $51^{\circ} 56^{\prime} 15.76^{\prime \prime} \mathrm{W}$. This experiment used young and asymptomatic leaves, collected in July of 2006. During that period, plants were under hydric stress, with the temperature at $27^{\circ} \mathrm{C}$, and $34 \%$ relative air humidity. The materials were processed immediately after collected.

Isolation of endophyte fungi

Leaf surface disinfection was done using a modified methodology by Pamphile and Azevedo (2002). Leaves placed in the laminar flow chamber were immersed in $0.1 \%$ Tween 80 and rinsed in distilled water. They were then immersed in 5\% sodium hypochlorite solution for $8 \mathrm{~min}$, then subjected to constant and vigorous shaking in $70 \%$ ethanol for $1 \mathrm{~min}$; once more in $70 \%$ ethanol for $30 \mathrm{sec}$; finally they were rinsed twice in sterilized distilled water. A $100 \mu \mathrm{L}$ aliquot of water from the last rinsing was placed in Petri dishes containing BDA medium (Smith and Onions 1983), supplemented with $50 \mu \mathrm{g} \cdot \mathrm{mL}^{-1}$ tetracycline (Sygma). Materials were incubated under the same conditions of samples for negative control and disinfected leaves were aseptically cut into fragments of 5 to $7 \mathrm{~mm}^{2}$, supplemented with $50 \mu \mathrm{g} \cdot \mathrm{mL}^{-1}$ tetracycline (Sygma).

Morphology-based characterization and identification of endophyte fungi

The endophyte isolates were cultivated in PDA medium and used the micro-culture technique to identify microscopic structures, following Kern and Blevins (1999). The cytological and morphological characteristics of endophytes were challenged by the identification keys (Barnett and Hunter 1972; Ellis 1971).

\section{DNA extraction}

All isolates used in this investigation were obtained from a monospore colony. The methodology used for genomic DNA extraction followed Pamphile and Azevedo (2002). However, fungi were not grown in a liquid medium, but instead on a cellophane membrane for 5 days, at $28^{\circ} \mathrm{C}$ in BDA medium (Smith and Onions 1983). Spectrophotometry (Spectrun SP2000 UV) calculated DNA concentration and purity was determined by OD260/OD280, described by Maniatis et al. (1989). DNA integrity was tested by $1 \%$ agarose gel electrophoresis. The concentration of genomic DNA was adjusted for final concentration of $10 \mathrm{ng}$. $\mathrm{mL}^{-1}$ for rDNA amplification.

\section{Amplification and purification of rDNA's ITS}

The fragments of ITS1-5.8S-ITS2 were amplified by primers ITS1 and ITS4 (White et al. 1990). The amplification of ITS regions of rDNA followed the methodology by Magnani et al. (2005). The amplified fragments were analyzed by $1 \%$ agarose gel electrophoresis. The products of amplification of ITS1 - 5.8S - ITS2 region of rDNA of the endophyte fungi strains were purified with GFX PCR DNA and the Gel Band Purification Kit (Amersham Biosciences).

Sequencing of the rDNA ITS regions and phylogenetic analysis

Sequencing of the rDNA ITS1 - 5.8S - ITS2 region was undertaken following Magnani et al. (2005). The amplification was performed in a MJ thermocycler (MJ Research, Inc.PTC-100) and the sequencing was achieved in MegaBace TM 1000 sequencer (Amersham Biosciences). The injection and electrophoresis conditions were respectively 2 $\mathrm{Kv} / 60 \mathrm{~s}$ and $6 \mathrm{Kv} / 230 \mathrm{~min}$. Endophyte fungi were identified by analysis of DNA sequences of ITS1 - 5.8S - ITS2. A BLAST search was used to find the closest matched sequences in the GenBank database (Altschul et al. 1990). Fungi sequences employed by the authors and other related sequences were multiple and aligned with Bioedit (Hall 2005). These sequences were aligned and a phylogenetic tree was constructed by MEGA 3.1 (Kumar et al. 2004) with the neighbor-joining method (Saitou and Nei 1987), using pdistance for nucleotides with the pair-wise gap deletion option and using a bootstrap with 10,000 repetitions. The nucleotide sequences obtained in this study have been submitted to the GenBank and assigned accession numbers EU878417 to EU878438.

Histological study of host colonization by endophytes assessed by light microscopy

The anatomy of leaves was analyzed for endophyte fungi in their interior. The methodology followed Guerrits (1991); however it was modified with inclusion of material in paraffin. Leaves were collected, surface disinfected and incubated in BDA medium at $28^{\circ} \mathrm{C}$ for $24 \mathrm{hrs}$ to $72 \mathrm{hrs}$ to stimulate the growth of endophytes. The leaves were removed from the medium, transferred to flasks and fixed in Bouin solution (70\% picric acid, 20\% formaldehyde and $10 \%$ glacial acetic acid) for 24 hours. The fixer was removed and leaves were maintained in $70 \%$ alcohol for 2 hours. This procedure was repeated for the same period, but the $70 \%$ alcohol was substituted by $80^{\circ}$ and $90^{\circ}$ absolute ethanol, ethanol with xylol $(1: 1 \mathrm{v} / \mathrm{v})$, and finally with xylol. The content was again removed and the bath was repeated in xylol for 40 and 30 minutes, respectively. Xylol was then removed and the leaves underwent 3 paraffin baths. After this procedure, the leaves were inserted in paper blocks with hot paraffin and maintained in a vertical position until dried and polymerization of the paraffin before receiving a transversal cut. The blocks were maintained for at least 24 hours in the mold before the cut. The block containing plant fragments was cut with a rotation steel razor microtome. Whereas the thickness of the cut was $0.7 \mathrm{~mm}$, and the leaf cuts were re-hydrated to avoid dehydration. 
The coloration of fragments was done by Trypan Blue (TB) and Sudan IV (SIV), adapted from Barrow (2003). The laminae were fixed and observed by an optical microscope image capture system (Zeiss Axioskop 2 Plus).

Scanning Electron Microscopy (SEM)

The Scanning Electron Microscopy (SEM) was undertaken according to Pamphile et al. (2008b) with the glutaraldehyde-fixing protocol and a freeze-fracturing preparation. These fragments were covered with a fine gold layer $\left(260 \mathrm{~s}, 50 \mathrm{MA}\right.$, at $\left.27^{\circ} \mathrm{C}\right)$ in a metallic covering (sputtering) apparatus. The metal-covered fragments were analyzed in a SEM emission field at $5 \mathrm{kV}$ and $7 \mathrm{~mm}$ distance. A critical point dryer (Balzers-CPD 030), metal-coater (Balzers-MED 010), and SEM (Zeiss-DSM940A) were employed for the Scanning Electron Microscopy at the Research Nucleus in Applied Electronic Microscopy for Agricultural and Cattle-Breeding Research (NAP/MEPA) of the University of São Paulo (ESALQ/USP).

\section{RESULTS}

Isolation and identification of endophytic microorganisms of Luehea divaricata

From all the fragments that show fungal growth, in the 1000 leaf samples from two L. divaricata trees, one hundred and twenty-seven endophytes were randomly selected for isolation into an axenic culture on PDA, for further analysis. Those 127 endophyte isolates were grouped into forty-six different morpho-groups according to their cytological and morphological characteristics. This microculture technique was not sufficient to identify all the morphotype genera. Approximately $70 \%$ of the fungi isolates failed to form reproductive structures in BDA medium at $28^{\circ} \mathrm{C}$, in 7 to 15 days of incubation. The genus and species of 22 isolates were determined by ITS1-5.8SITS2 sequencing of L. divaricata endophyte fungi. The following genera were identified: Alternaria, Cochliobolus, Diaporthe, Epicoccum, Guignardia, Phoma, and Phomopsi. PCR products by the amplification of rDNA's ITS1, 5.8S and ITS2 regions were approximately $516 \mathrm{bp}$. Results from macroscopic and microscopic characteristics of endophytic colonies for taxonomic evaluation purpose, were congruent with results of ITS DNA sequence blasting analysis of these isolates. The genus Cephalosporium was also identified by cytological analysis with identification keys. Table 1 shows L. divaricata endophyte isolates based on similarity to those at the NCBI data bank.

Phylogenetic analysis of $L$. divaricata endophyte isolates based on rDNA sequencing data

Figure 1 shows phylogenetic analysis based on rDNA sequencing data of 21 endophyte isolates of L. divaricata coupled to the retrieved sequences from the GenBank. The majority lineages of fungi were resolved with bootstrap

Table 1

Isolated and identified endophytes with relationship to the genus or species and the identity percentage found in NCBI (National Center for Biotechnology Information website).

\begin{tabular}{|c|c|c|c|}
\hline Endophyte isolates & Closely related fungal sequence & Accession $n^{\circ}$ of closest hit & Identity $(\%)$ \\
\hline G1 A2-44 & Alternaria tenuissima & EF504997.1 & 97 \\
\hline G2 A1-32 & Alternaria alternata & EU520077.1 & 99 \\
\hline G3 A1-34 & Phomopsis phyllanthicola & AY620819.1 & 95 \\
\hline G5 A1-59 & Epicoccum nigrum & AB369423.1 & 97 \\
\hline G6 A1-20 & Cochliobolus intermedius & AF071327.1 & 95 \\
\hline G8 A1-01 & Guignardia vaccinii Guignardia mangiferae & EU167584.1 EU677817.1 & 9999 \\
\hline G9 A1-40 & Cochliobolus lunatus & DQ836800.1 & 94 \\
\hline G12 A2-39 & Phomopsis phyllanthicola & AY620819.1 & 95 \\
\hline G15 A1-23 & Phomopsis sp. & EU002925.1 & 94 \\
\hline G18 A2-24 & Phomopsis chiamonanthi & AY622993.1 & 96 \\
\hline G23 A1-62 & Diaporthe helianthi & AJ312356.1 & 98 \\
\hline G24 A2-28 & Phoma herbarum & AB369456.1 & 98 \\
\hline G26 A1-03 & Phomopsis sp. & EU256482.1 & 97 \\
\hline G27 A2-41 & Phomopsis sp. & EU002918.1 & 95 \\
\hline G29 A2-48 & Phomopsis sp. & EU002922.1 & 93 \\
\hline G35 A2-18 & Phomopsis chiamonanthi & AY622993.1 & 94 \\
\hline G36 A1-22 & Phomopsis sp. & EU256482.1 & 96 \\
\hline G37 A1-65 & Phomopsis sp. & EF687935.1 & 97 \\
\hline G39 A2-59 & Diaporthe sp. & AB245446.1 & 96 \\
\hline G44 A1-14 & Phomopsis sp. & EF687935.1 & 95 \\
\hline G45 A2-42 & Phomopsis sp. & DQ286285.1 & 92 \\
\hline G46 A2-58 & Phomopsis chiamonanthi & AY622993.1 & 96 \\
\hline
\end{tabular}




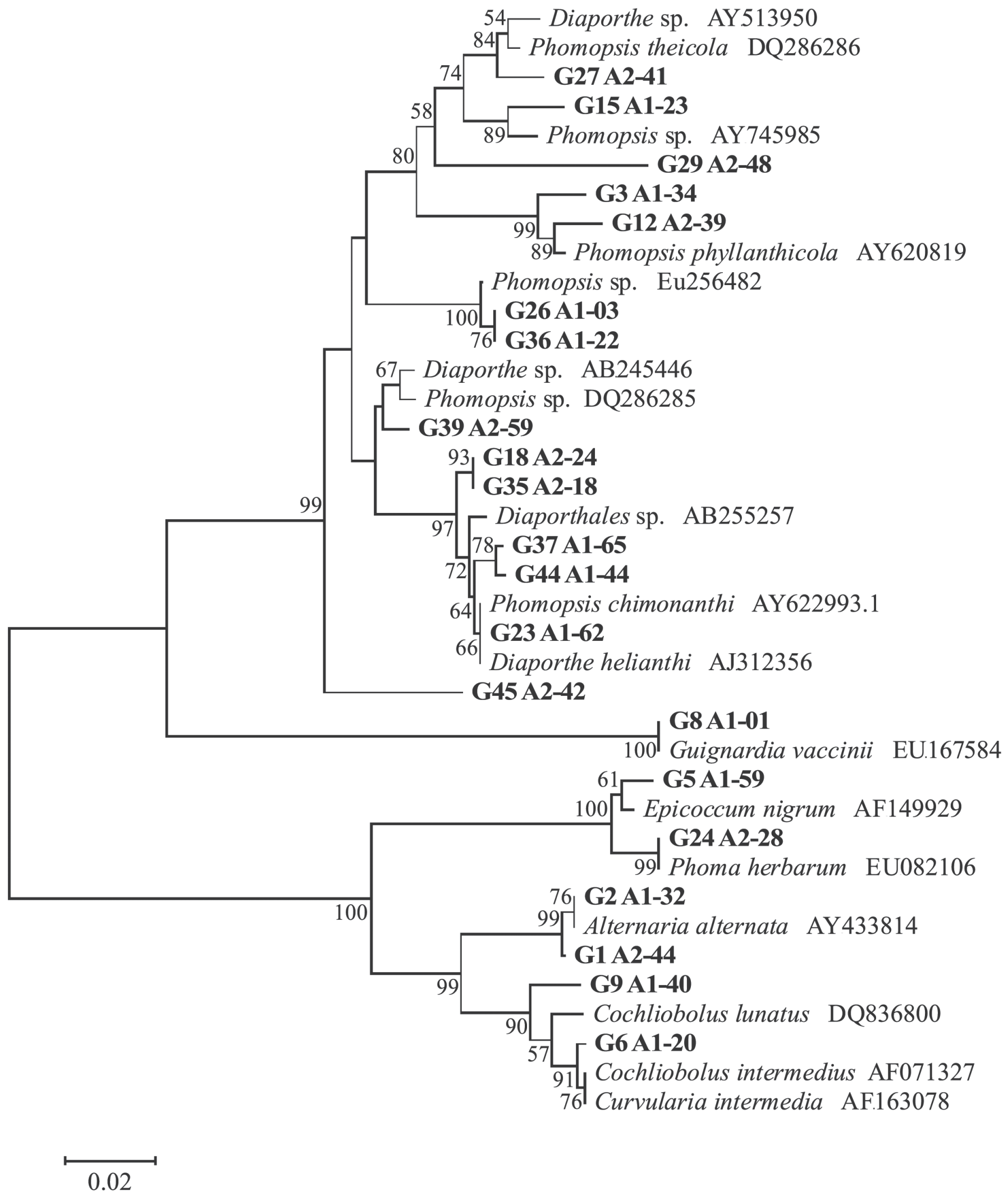

Figure 1: Phylogenetic tree constructed by the neighbor-joining method using "p-distance" for nucleotides, with the options of gap pairwise deletion choice. The codes on the right represent the endophytic isolates of $L$. divaricata belonging to the families Valsaceae (G27 A2-41, G15 A1-23, G29 A2-48, G3 A1-34, G12 A2-39, G26 A1-03, G36 A1-22, G39 A2-59, G18 A2-24, G35 A2-18, G37 A1-65, G44 A1-44, G23 A1-62 and G45 A2-58), Botryosphaeriaceae (G8 A1-01), Leptophaeriaceae (G5 A1-59), Pleosporaceae (G24 A2-28, G2 A1-32, G1 A2-44, G9 A1-40, G6 A1-20). The sequences from GenBank are indicated by database code. The numbers above and underneath each knot indicate the frequency (in percentage) of each branch in bootstrap analyses of 10,000 replicates. 
support superior to $54 \%$, inferred with neighbor joining [NJ]. Two main clades could be obtained; one including lineages belonging to the Valsaceae and Botryosphaeriacea families and another clade including lineages from Leptophaeriaceae and Pleosporaceae families.

\section{Light Microscopy}

Figure 2 ( $a$ and $b$ ) shows fragments of L. divaricata leaves without any previous incubation and 3-day-incubated fragments. The increase of endophyte colonization may be seen in the intra- and intercellular spaces of esclerenchyma, spongy parenchyma, vascular bundle and palisade parenchyma. The intense colonization of the palisade parenchyma may be observed with and without previous incubation of leaves. A larger colonization of the vascular bundle is perceived after incubation. Figure 2 (c) shows bluedyed hyphae within inter- and intracellular spaces of the palisade parenchyma and esclerenchyma.

\section{Scanning Electron Microscopy (SEM)}

Leaves of L. divaricata, incubated for 24 hours and analyzed by a Scanning Electron Microscopy, revealed hyphae of endophyte fungi inside the cells and in the intracellular spaces. Figure 3 shows the endophytes leaving the interior of the leaf structures and intensely colonizing leaf tissue. A large colonization of endophyte fungi may be observed on the broken foliar lamina.

\section{DISCUSSION}

The isolation frequency found in this investigation was high and all sampled fragments presented fungi growth. In accordance with Arnold (2008), the high abundance of inoculum in the air column, and the apparently universal receptivity of tropical plants to colonization by endophytic fungi, leads to high infection rates in mature foliage of tropical trees. Arnold (2002 and Arnold, 2008) recovered

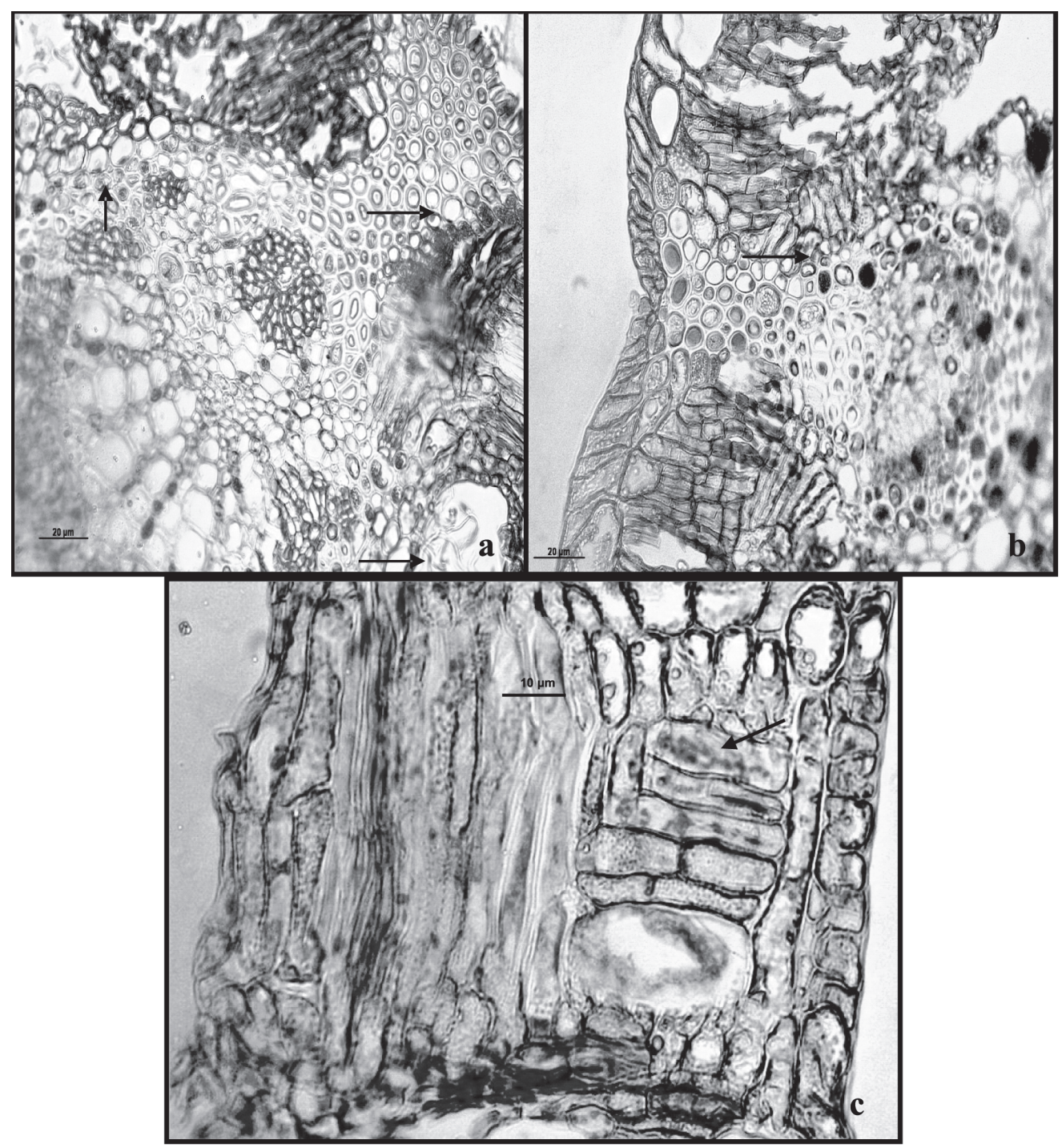

Figure 2: The cross-sections of leaves of L. divaricata stained with Trypan Blue and Sudan IV. Amplified 200x. a) Leaf cut without incubation. The arrow indicates the smaller colonization of endophytes, blue stained, in most intracellular spaces; b) leaves incubated for 3 days to $28^{\circ} \mathrm{C}$ before cutting; c) mycelium blue stained in the area of inter and intracellular palisade parenchyma and esclerenchyma tissue. The arrow indicates the presence of endophytes, blue stained in most of intracellular spaces. 


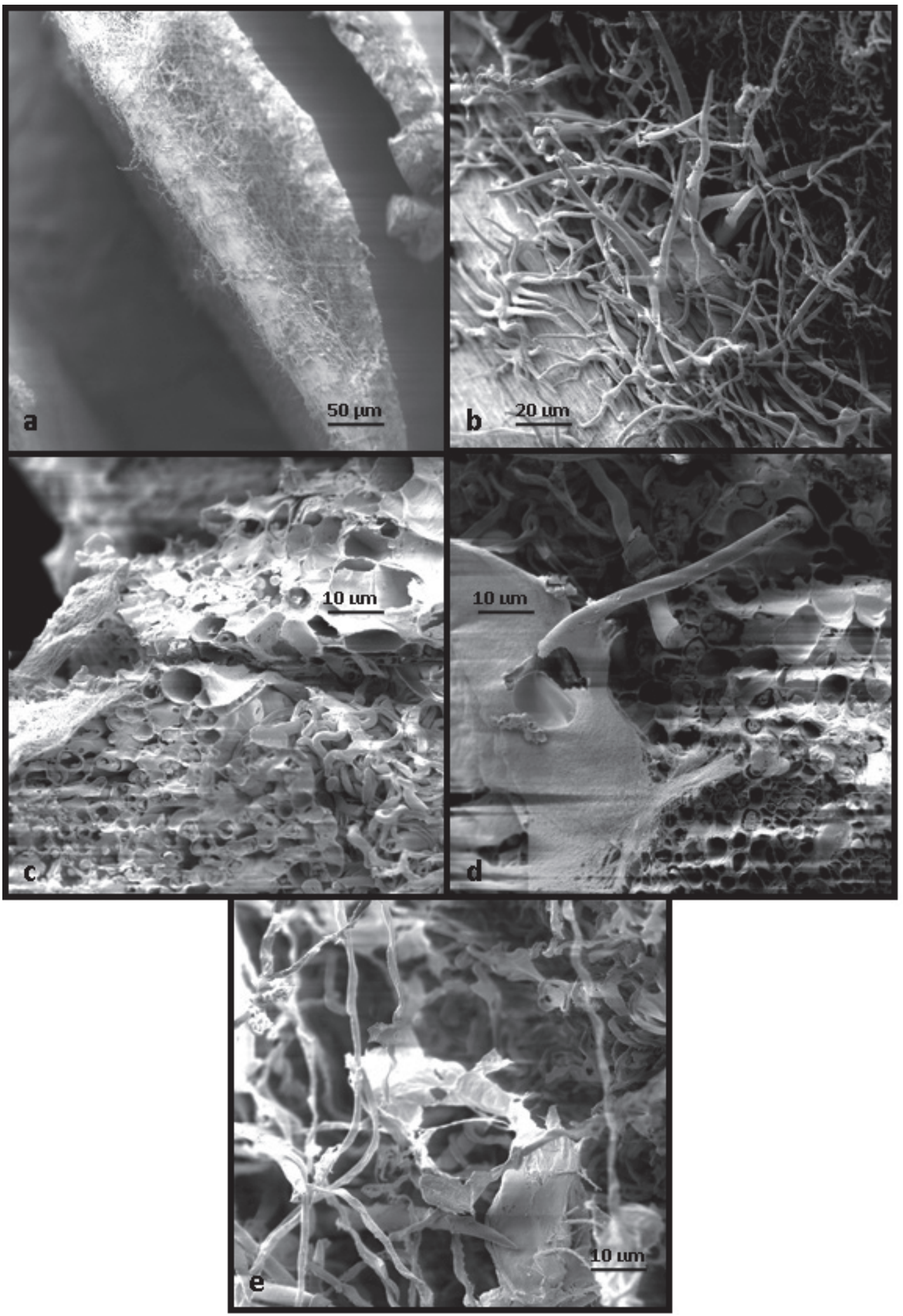

Figure 3: Scanning electron microscopy of leaves of $L$. divaricata incubated for 24 hours, demonstrating the colonization by endophyte fungi. a) foliar lamina (50 $\mu \mathrm{m}$ bar) b: hyphae of endophyte fungi emerging from leaf fragment (20 $\mu \mathrm{m} \mathrm{bar}) ; \mathrm{c}$ and d) hyphae in the intracellular spaces, emerging from inside the cells $(10 \mu \mathrm{m}$ bar); e) different morphologies of hypha. 
endophytic fungi from $100 \%$ of mature leaves sampled from 28 species of woody plants representing 24 families and 14 orders of angiosperms. Cannon and Simmons (2002) in their study on the tropical palm trees of Guyana, verified that 9 to $23 \%$ of the 2.520 fragments assayed did not have any endophyte growth. Since the assayed fragment size is relevant, it might interfere in the number of endophyte isolates. If the size of the assayed fragment is large, the microorganisms of the fringes may impair the growth of the most distant ones. Assaying small fragments is the key to obtain a higher number of isolates. The use of about 5 to 7 $\mathrm{mm}^{2}$ fragments was effective for achievement of endophytes, which occurs in higher frequency of isolation. Herre et al. (2005) suggested that most leaves are saturated by endophytic fungi (i.e. contain endophytes in $100 \%$ of $2 \mathrm{~mm}^{2}$ tissue segments) within 3-4 weeks after emergence. Pamphile and Azevedo (2002) obtained a frequency of colonization that ranged from 15 to $74 \%$ when investigating endophyte microorganisms of different inbred lines of maize. Although the size of fragments could reflect the kind of fungi isolated; some are fast growing and aggressive in agar culture. Hyde and Soytong (2008), in discussing the fungal endophyte dilemma, pointed out that probably the most important, yet rarely mentioned flaw in endophyte studies, is the fact that pieces of plant materials are placed on agar and the endophytes isolated in any study are those that grow out, and there are numerous references to fungi being unable to grow in culture. However, according with these authors, when endophytes are isolated by traditional methodology, it is conceivable to only obtain the faster growing culturable fungi and it is highly probable that some or even numerous endophytes are never isolated.

Hyde and Soytong (2008) also considered that any further work on endophytes resulting from traditional methodology must accept that the data has inherent problems, which includes the fact that isolated biodiversity is likely to be much lower than that actually present and that isolated endophyte communities will be biased towards faster growing fungi that are capable of growing rapidly on the media used, like Colletotrichum, Phomopsis, Phyllosticta, and Xylaria species.

Twenty-two out of the 127 cultivable endophyte fungi isolated from $L$. divaricata could be identified for molecular and morphologic analysis. Although the most often related sequence was the uncultured endophyte fungus clone 55-1309 (Accession EF 50 4997.1) among the GenBank sequences related to endophyte isolate G1 A2-44 (with 97\% identity and total score above 785). This research has employed the sequence of Alternaria tenuissima (Accession AJ 867284.1) owing to the genus being concordant with identification by morphological and cytological analyses with the taxonomical classification keys for Alternaria alternata. The same procedures were taken with regard to isolates G2 A1-32 and G5 A1-59, where different species had similar scores and maximum identity. However, the access number in this research is that which most agree with the morphological or cytological characteristics of the isolates among the sequences of highest similarity.

Isolate G8 A1-01 revealed molecular identity with two different species of the genus Guignardia sp., or rather, G. mangiferae and G. vaccinii. The two access numbers have been referenced since undoubtedly the isolate belongs to genus Guignardia.

Isolate G9 A1-40 had a higher identity with sequences belonging to Dothideomycete sp. (EU 680523.1; EU 680514.1 and EU 680517.1), or rather, Macrophomina sp. (DQ682587.1) and Cochliobolus lunatus (DQ836800.1). The genus that most agrees with the characteristics of the endophyte isolate was Cochliobolus lunatus. Since Dothideomycete is a class of the phylum Ascomycota, the genus to which Cochliobolus also belongs (the perfect state of Curvularia family is Pleosporaceae).

Sequence ITS1 - 5.8 S - ITS 2 of rDNA from isolate G45 A2-42 has the highest identity (92\% identity and a total score of 682) with genus Phomopsis sp. (DQ 286285.1) and Diaporthe helianthi (AY 485749.1, AY 485748.1, AY 485747.1, AY 485746.1, and AJ 312366.1). Since Phomopsis is the conidial state of Diaporthe, the endophyte isolate belongs to the genus Phomopsis because no sexual structures were identified in endophyte isolates.

The data obtained reinforced the need to undertake an investigation based on the micro-culture of the above endophyte molecular identification (ITS1 - 5.8S - ITS2 rDNA), comparing cytological and morphological characteristics with already known identity keys for a better taxonomic characterization. Arnold et al (2007) considers that GenBank matches, if based on well identified taxa, can be sufficient for estimating species richness and upper level taxonomic placement. However, the prevalence of unnamed samples in GenBank, the occurrence of misidentified taxa, and the rapid growth of the database that yielded highly divergent matches at the genus and family levels when BLAST results from 2003 and 2004 were compared; all underscore the need for caution when estimating taxonomic composition based on BLAST results alone.

Phomopsis, with $77 \%$ of isolates, was the most frequent genus. The above data corroborate results by Chareprasert et al. (2006). They found the Phomopsis genus to be the most frequent endophyte fungus isolated from the leaves, both young and adult, of Tectona grandis L. and Samanea saman Merr. The study of the endophyte diversity of fungi in cacao trees (Theobroma shark L.) (Rubini et al., 2005), within the context of 150 randomly chosen endophytes, partially characterized the population (52 endophyte isolates) by rDNA sequencing. Results showed that the cultivable endophyte fungi associated with the cacao cultivars mainly belonged to the Ascomycete group. In fact, the families Botryosphaeriaceae, Valsaceae and Nectriaceae were the most frequent. The fungi Fusarium spp. was the dominant genus and showed the highest diversity when endophytes and other fungi were phylogenetically analyzed. Similarly, $L$. divaricata endophytes, identified in this research, belonged to Botryosphaeriaceae, Valsaceae, Leptosphaeriaceae, and Pleosporaceae families. Arnold et al (2007) investigating the diversity and phylogenetic affinities of foliar fungal endophytes in loblolly pine, observed that cultured endophytes represented both a single clade within the Basidiomycota (seven isolates) and numerous lineages of Ascomycota. The Ascomycota cultured endophytes were distributed among the Sordariomycetes, Dothideomycetes, Eurotiomycetes, and Leotiomycetes. The fungi Phomopsis and Diaporthe were the most frequent genus in the L. divaricata endophytic isolates group. Rodrigues and Menezes (2002) 
obtained 71 endophyte fungi from caupi seeds and reported that the most frequent genus was Aspergillus, Penicillium, and Fusarium. The genera Aspergillus and Penicillium were predominant in $68.08 \%$ of the colonies. Tejesvi et al. (2006) isolated fungal endophytes from the inner bark segments of ethnopharmaceutically important medicinal tree species, namely: Terminalia arjuna, Crataeva magna, Azadirachta indica, Holarrhena antidysenterica, Terminalia chebula, and Butea monosperma; additionally, the endophytic species Fusarium, Pestalotiopsis, Myrothecium, Trichoderma, Verticillium, and Chaetomium were frequently observed.

The separation of different $L$. divaricata endophytes from the genus Phomopsis in different groups observed in the phylogenetic dendrogram, including the 15 Phomopsis and Diaphorte endophyte isolates coupled to the retrieved sequences from the GenBank, indicate intra-species variability (Figure 1). They could be separated into three main clades. One clade included the following endophytes: G27 A2-41, G15 A1-23, G29 A2-48, G3 A1-34, G12 A2-39, G26 A1-03, and G36 A1-22. Another clade with endophytes included: G39 A2-59, G18 A2-24, G35 A2-18, G37 A1-65, G44 A1-44, and G23 A1-62. The endophyte G45 A2-42, which had high ITS BLAST affinity for Phomopsis sp. (Dec 2008), belonged to the third clade alone. The first clade could be divided into two different sub-clades, one with G27 A2-41, G15 A1-23, G29 A2-48, G3 A1-34, and G12 A2-39. The other sub-clade would be formed by G26 A1-03 and G36 A1-22 endophytes. The second Phomopsis/Diaporthe main clade could be separated into a sub-clade with endophyte G39 A259 plus retrieved sequences from GenBank. The other subclade would be formed by endophytes G18 A2-24, G35 A218, G37 A1-65, G44 A1-44, and G23 A1-62. Steiner et al. (2006) built a phylogenetic dendrogram based on the rDNA $18 \mathrm{~S}$ genes and on the transcribed internal spacer (ITS) of 12 Clavicipitaceous (ascomycetes) endophytic fungi and an epibiotic fungus (which grows on the plant's surface and feeds on its nutrients) of dicotyledons (Convolvulaceae). The same researchers observed that although the epibiotic fungus belonged to the family Clavicipitaceae (Ascomicota), none of the other endophytes did.

Microscopic analysis of $L$. divaricata leaves showed the interactions between the host plant and endophyte fungi. Light microscopy confirmed the presence of endophytes in L. divaricata leaves (coupled to a significant increase in colonization after 3 days of previous incubation on PDA medium at $28^{\circ} \mathrm{C}$ ). Staining with Sudan IV and Trypan-Blue revealed the endophyte colonization of $L$. divaricata leaves, including intracellular fungi growth. Gómez-Vidal et al. (2006), studying endophyte colonization of palm leaves (Phoenix dactylifera L.) by endophyte entomopathogenic fungi (with light microscopy and stained with Trypan-Blue $0.05 \%$ in lactic acid for $45 \mathrm{~min}$, at $60^{\circ} \mathrm{C}$ ), reported the presence of $B$. bassiana colonizing the parenchyma, mainly in intercellular spaces, after the incubation of leaves for 8 days. After 13 days of incubation, the same authors observed a high hyphae density colonizing intra- and intercellularly in the parenchyma. These data agree with those observed in L. divaricata, in which intra and intercellular colonization increased with previous incubation of the analyzed fragments. Gómez-Vidal et al. (2006) stated that the colonization of the parenchyma by entomopathogenic endophyte fungi might be explained by starch degradation.
Furthermore, the colonization of the vascular bundle by endophytes in palm leaves was also reported. These data agree with those reported in this research on light microscopy results on L. divaricata leaves after 3 days of pre-incubation of leaf fragments on PDA after superficial disinfection. Through this technique, the structural aspects of the interaction between the endophyte fungi and the plant, above all in the parenchyma tissue, could be verified. The above results were confirmed by a Scanning Electron Microscopy. Souza et al. (2004), using SEM, observed plantmicrobe interactions between maize (Zea mays L.) and endophyte bacteria in the leaf tissue through the application of the osmium fixation technique. The technique favored the observation of intracellular space of maize leaves infected by endophyte bacteria. The threedimensional configuration and arrangement of endophyte colonies inside the host plant leaf tissue were visible. In terms of the study of endophyte-L.divaricata interactions, to the authors' knowledge this is the first SEM demonstration of inter and intracellular colonization of host plants by endophyte fungi. Similar studies, albeit using Citrus limon, Durán et al. (2005), failed to view endophyte fungi within leaf cells and perceived only hyphae attached to the surface of cells in the parenchyma.

Although the literature characterizes the intracellular colonization phenomenon as sporadic (Azevedo et al., 2002; Peixoto Neto et al., 2002), this analysis shows the clear visualization (by light microscopy and Trypan Blue staining) of endophytes inhabiting the cells of the host plant $L$. divaricata. This shows that intracellular colonization is as frequent as intercellular colonization, which has been corroborated by SEM. SEM analysis also revealed different hyphae of endophyte fungi in the cells. The initial incubation of leaves (that were previously superficially disinfected according to the method of isolation of endophytes on PDA medium at $28^{\circ} \mathrm{C}$, prior to light and SEM preparation) was held to reflect the development of endophytes within leaves in a positive condition for endophytes, several days before they depart from the plant tissues and develop into a culture medium. In that way, the incubating process would facilitate the endophyte development and growth in local tissue as their initial visualization increases. The plant tissues had relative preservation in a condition of humidity and nutrients (PDA medium) and under these incubating conditions they maintained relative turgor and cell integrity, without showing indications of senescence (yellowing). Price et al (2008), working with wallflowers, considered that leaves could be characterized within one whorl and were assigned to seven developmental groups based on relative size and chlorophyll content. At stage 5, leaves showed the first signs of yellowing, indicating senescence, and this corresponded to a $20 \%$ reduction in chlorophyll levels. Price et al (2008) pointed out that in leaves, the dry-weight-fresh-weight ratio started to rise after stage 5; while protein loss started after stage 4 , again preceding the start of visual signs of senescence.

However, Arnold (2008) highlighted that several researchers have suggested that endophytes are saprotrophs waiting to happen; they undergo a latent phase as a prelude to rapid growth, following leaf death. Consequently, Arnold (2008) said that endophytes might resemble tropical pioneer species - but with persistence in leaves instead of a soil seed 
bank. From that point of view, the light microscopic observations of detached leaves of L. divaricata incubated for 3 days could also reflect initial sapro-endophytic behavior. Hyde and Soytong (2008) stated that several studies provide evidence to support the hypothesis that saprobe host specificity in plants is dependent on internal endophytes, while others indicate that host components may regulate the endophytes within. Hyde and Soytong (2008) pointed out that whatever the reason, it is clear that many endophytes in leaves are host, host genus or host family specific, and that this specificity must depend on factors such as initial endophyte colonization and/or substances within leaves and wood.

The current authors were successful in verifying that rDNA sequence analysis, associated with traditional methods of fungus identification by cytological analysis, could identify several endophyte fungi isolates from $L$. divaricata. This fact demonstrates that both tools are effective in the study of endophyte taxonomy. Furthermore, the phylogenetic analysis of rDNA sequences revealed the intraspecies variability in the genus Phomopsis sp. Light microscopy and Scanning Electron Microscopy techniques revealed the presence of extensive and widely disseminated colonizations of the endophyte fungi throughout the leaves in the palisade parenchyma, esclerenchyma, adaxial epidermis, and vascular bundle. A close interaction of endophytes in multiple structural sub-niches in the host plant is thus suggested.

\section{ACKNOWLEDGEMENTS}

We would like to thank Dr. Elliot Watanabe Kitajima of ESALQ/USP for the use of the Scanning Electron Microscopy.

\section{REFERENCES}

ALICE CB, SIQUEIRA NCS DA, MENTZ LA, SILVA GA DE ABE, JOSÉ KFD (1995) Plantas medicinais de uso popular: atlas farmacognóstico. ULBRA, Canoas.

ALTSCHUL SF, GISH W, MILLER W, MYERS EW, LIPMAN DJ (1990) Basic local alignment search tool. J Mol Biol 215: 403-410.

ARNOLD AE (2008). Endophytic fungi: hidden components of tropical community ecology. In Carson WP, Schnitzer SA (eds) Tropical Forest Community Ecology, Wiley-Blackwell, Oxford.

ARNOLD AE, HENK DA, EELLS RL, LUTZONI F, VILGALYS R (2007) Diversity and phylogenetic affinities of foliar fungal endophytes in loblolly pine inferred by culturing and environmental PCR. Mycologia 99: 185-206.

ARNOLD AE, MEJÍA LC, KYLLO D, ROJAS EI, MAYNARD Z, ROBBINS N, HERRE EA (2003) Fungal endophytes limit pathogen damage in Tropical tree. Proc Nat Acad Sci 26: 15649-15654.

AZEVEDO JL, JÚNIOR WM, ARAÚJO WL DE, PEREIRA JO (2002) Microrganismos endofíticos e seu papel em plantas tropicais. In: Serafini LA, Barros MN, Azevedo, LA (eds) Biotecnologia: avanços na agricultura e na agroindústria, EDUCS, Caxias do Sul.

AZEVEDO JL, MACCHRON, WJR, PEREIRA JO, ARAÚJO WL (2000) Endophytic microrganisms: a review on insect control and recent advances on tropical plants. Eletronic J Biotechnol 3: 40-65.

BARNETT HL, HUNTER BB (1972) Illustrated genera of imperfect fungi 3 ed. Minnesota: Burgess Publishing Company.

BARROW JR (2003) Atypical morphology of dark septate fungal root endophytes of Bouteloua in arid southwestern USA Rangelands. Mycorrhiza 13: 239-247.

CANNON PF, SIMMONS CM (2002) Diversity and host-preference of leaf endophytic fungi in the Iwokrama Forest Reserve, Guyana. Mycologia 94: 210-220.
CARROLL GC, CARROLL FE (1978) Studies on the incidence of coniferous needle Endophytes in the Pacific Northwest. Canadian J Bot 56: 3034-3043.

CHAREPRASERT C, PIAPUKIEW J, THIENHIRUN S, WHALLEY AJS, SIHANONTH P (2006) Endophytic fungi of teak leafs Tectona grandis L. and rain tree leafs Samanea saman Merr. World J Microbiol \& Biotechnol 22: 481-486.

DURÁN EL, PLOPER LD, RAMALLO JC, GRANDI RAP, GIANCOLI $\mathrm{ACH}$, AZEVEDO JL (2005) The foliar fungal endophytes of Citrus limon in Argentina. Canadian J Bot 83: 350-355.

ELLIS MB (1971) Hyphomycetes. Commonwealth Mycological Institute Cambrian News: Aberystwyth, U.K.

GÓMEZ-VIDAL S, LOPEZ-LORCA LV, JANSSON HB, SALINAS J (2006) Endophytic colonization of date palm (Phoenix dactylifera L.) leafs by entomopathogenic fungi. Micron 37: 624-632.

GUERRITS PO (1991) The application of glycol methacrylate in histotechnology; some fundamental principles. Department of Anatomy and Embryology, Gröningen, Netherlands.

HALL T (2005) BioEdit: Biological Sequence Alignment Editor for Windows 95/98/NT/XP.

HERRE, EA, VAN BAEL SA, MAYNARD Z, ROBBINS N, BISCHOFF J, ARNOLD AE, ROJAS E, MEJIA LC, CORDERO RA, WOODWARD C, KYLLO DA (2005). Tropical plants as chimera: some implications of foliar endophytic fungi for the study of host plant defense, physiology, and genetics. In. Burslem DERP, Pinard MA, Hartley SE (eds) Biotic Interactions in the Tropics, Cambridge University Press, Cambridge.

HYDE KD, SOYTONG K (2008) The fungal endophyte dilemma. Fungal Diversity 33: 163-173.

KERN ME, BLEVINS KS (1999) Micologia Médica. Premier, São Paulo.

KUMAR S, TAMURA K, NEI M (2004) MEGA3: Integrated software for Molecular Evolutionary Genetics Analysis and sequence alignment. Briefings in Bioinformatics 5: 150-163.

LORENZI H (2000) Árvores Brasileiras: Manual de Identificação e Cultivo de Plantas Arbóreas do Brasil. 3 rd. Editora Nova Odessa, Instituto Plantarum de Estudos da Flora, São Paulo.

MAGNANI M, FERNANDES T, PRETE CEC, HOMECHIM M, ONO EYS, VILAS-BOAS LA, SARTORI D, FURLANETO MC, FUNGARO MHP (2005) Molecular identification of Aspergillus spp. isolated from coffee beans. Scientia Agricola 62(1):45-49.

MANIATIS T, FRITSCH EF, SAMBROOK J (1989) Molecular Cloning: A Laboratory Manual. New York: Cold Spring Harbour laboratory.

PAMPHILE JA, AZEVEDO JL (2002) Molecular characterization of endophytic strains of Fusarium verticillioides (Fusarium moniliforme) from maize (Zea mays.L). World J Microbiol Biotechnol18(5): 391-396.

PAMPHILE JA, GAI CS, PILEGGI M, ROCHA CLMSC, PILEGGI SAV (2008) Plant-microbe interactions between host and endophytes observed by Scanning Electron Microscopy (SEM). In: S. Sorvari and A.M. Pirttilä (eds.) Prospects and Applications for Plant-Associated Microbes. A Laboratory Manual, Part A: Bacteria.Finland: BBI (BioBien Innovations). 184-189. (a)

PAMPHILE JA, PILEGGI M, GAI CS, ROCHA CLMSC, PILEGGI SAV (2008) Scanning Electron Microscopy (SEM). In: S. Sorvari and A.M. Pirttilä (eds.) Prospects and Applications for Plant-Associated Microbes. A Laboratory Manual, Part A: Bacteria Finland: BBI (BioBien Innovations). 9-13. (b).

PAMPHILE JA, ROCHA CLMSC DA, AZEVEDO JL (2004) Cotransformation of a tropical maize endophytic isolate of Fusarium verticillioides (synonym F. moniliforme) with gus A and nia genes. Genet Mol Bio 27(2): 253-258.

PEIXOTO-NETO PAS, AZEVEDO JL, ARAÚJO WL (2002) Microrganismos endofíticos. Biotecnoliga Ciência \& Desenvolvimento 29: 62-76.

PRICE AM, ORELLANA DFA, SALLEH FM, STEVENS R, ACOCK $R$, BUCHANAN-WOLLASTON V, STEAD AD, ROGERS H. A comparison of leaf and petal senescence in wallflower reveals common and distinct patterns of gene expression and physiology. Plant Physiol 147: 1898-1912.

RAI MK (2003) Plant-Derived Antimycotics. Haworth Press, Binghamton. REDBERG GL, HIBBETT DS, AMMIRATI JF JR, RODRIGUEZ R J (2003) Phylogeny and genetic diversity of Bridgeoporus nobilissimus inferred using mitochondrial and rDNA sequences. Mycologia 95(5): 836-845.

RODRIGUES AAC, MENEZES M (2002) Detecção de fungos endofíticos em sementes de caupi provenientes de Serra Talhada e de Caruaru, Estado de Pernambuco. Fitopatologia Brasileira 27(5): 532-537.

RODRIGUEZ RJ, WHITE JR JF, ARNOLD AE, REDMAN, RS (2009) 
Fungal endophytes: diversity and functional roles. New Phytologist 182: 314-330.

RUBINI MR, SILVA-RIBEIRO RT, POMELLA AWV, MAKI CS, ARAÚJO WL, SANTOS DR, AZEVEDO JL (2005) Diversity of endophytic fungal community of cacao (Theobroma cacao L.) and biological control of Crinipellis perniciosa, causal agent of Witches' Broom Disease. Internat J Biol Sci 1: 24-33.

SAIKKONEN K, WÄLI P, HELANDER M, FAETH SH (2004) Evolution of endophyte-plant symbioses. Trends in Plant Sci 9(6): 275-280.

SAITOU N, NEI M (1987) The neighbor-joining method: a new method for reconstructing phylogenetic trees. Mol Biol Evolutn 4: 406-425.

SMITH D, ONIONS AHS (1983) The preservation and maintenance of living fungi. Page Bros, Norwick.

SOUZA AO DE, PAMPHILE JA, ROCHA CLMS DA, AZEVEDO JL (2004) Plant-microbe interactions between maize (Zea mays L.) and endophytic microorganisms observed by Scanning Electron Microscopy. Acta Scientiarum Biol Sci 26(3): 357-359.

STEFANI FOP, BERUBE JA (2006) Biodiversity of foliar fungal endophytes in white spruce (Picea glauca) from southern Quebec. Canadian Journal of Botany 84(5): 777-790.

STEINER U, AHIMSA-MÜLLER MA, MARKERT A, KUCHT S, GROSS J,
KAUF N, KUZMA M, ZYCH M, LAMSHÖFT M, FURMANOWA M, KNOOP V, DREWKE C, LEISTNER E (2006) Molecular characterization of a seed transmitted clavicipitaceous fungus occurring on dicotyledoneous plants (Convolvulaceae). Planta 224 533-544.

TANAKA JCA, SILVA CC, FILHO BPD, NAKAMURA CV, CARVALHO JE, FOGLIO MA (2005) Constituintes químicos de Luehea divaricata Mart. (TILIACEAE). Química Nova 28: 834-837.

TEJESVI MV, MAHESH B, NALINI MS, PRAKASH HS, KINI KR, SUBBIAH V, SHETTY HS (2006) Fungal endophyte assemblages from ethnopharmaceutically important medicinal trees. Can J Microbiol 52(5): 427-435.

WHITE TJ, BRUNS TD, LEE S, TAYLOR JW (1990) Amplification and direct sequencing of fungal ribosomal RNA genes for phylogenetics. In: Innis, M. A., Gelfand, D.H., Sninsky, J.J. \& White, T.J. (eds). PCR Protocols: a guide to methods and appications. Academic Press, San Diego.

ZERVAKIS GI, MONCALVO JM, VILGALYS R (2004) Molecular phylogeny, biogeography and speciation of the mushroom species Pleurotus cystidiosus and allied taxa. Microbiol 150: 715-726. 